\title{
Synthesis and Analysis of Chromium and Calcium Doped $\mathrm{YMnO}_{3}$
}

\author{
MUKHAMETKALI MUSAGALIEVICH MATAEV ${ }^{1}$, GENNADY SEMENOVICH PATRIN², \\ KARIMA ZHAISANBEKOVNA SEITBEKOVA ${ }^{1 *}$, ZHANAR YLIASOVNA TURSINOVA ${ }^{1}$, \\ and MOLDIR RASHIDOVNA ABDRAIMOVA ${ }^{1}$
}
'Kazakh State Women's Teacher Training University, Almaty, 050000, Aiteke bi, 99, Kazakhstan. ${ }^{2}$ Institute of Engineering Physics and Radio Electronics Siberian Federal University,
Svobodny pr. 79, Krasnoyarsk, Russia.
${ }^{\star}$ Corresponding author E-mail: karimaseitbekova91@gmail.com

http://dx.doi.org/10.13005/ojc/350335

(Received: March 28, 2019; Accepted: June 05, 2019)

\begin{abstract}
The article presents the results of the synthesis and study of XRD of new chromite-yttrium manganese doped with alkaline earth metal Ca. For the first time synthesized sol-gel by double chromite-yttrium manganese with embedded calcium has a rhombus structure, with the number of formula units $Z=4$, the elementary cell of crystals has the following lattice parameters: $a=5.42 \AA ; b=7.51$ $\AA ; C=5.26 \AA$. The correctness of the results of $X$-ray studies confirm a satisfactory correspondance between the values of pycnometric and $X$-ray densities, as well as the coincidence of theoretical and experimental values of the inverse values of interplanar distances $\left(10^{4} / \mathrm{d}^{2}\right)$. The Miller indices $(\mathrm{hkl})$ refer to a face-centered rhombic singony. The crystal morphology of the synthesized powders was studied using a scanning electron microscope (SEM), which shows the dense structure of crystallites from 5 to 100 microns. Semi-quantitative elemental analysis confirms the embeddedness of calcium and chromium ions in the structure of the complex yttrium manganite as well as the monodispersed of the sample. The results of elemental analysis of complex chromite-manganite yttrium with the addition of calcium ions on the electron scanning microscope shows that the atomic percentage of the elements in the composition of the chromite-manganite yttrium, almost the same formula chromite-manganite composition- $\mathrm{Y}_{0,5} \mathrm{Ca}_{0,5} \mathrm{Cr}_{0,5} \mathrm{Mn}_{0,5} \mathrm{O}_{3}$.
\end{abstract}

Keywords: Sol-gel processes, $\mathrm{X}$-ray diffraction, Chromium doped manganite $\left(\mathrm{YMnO}_{3}\right)$,
Electron microscopy.

\section{INTRODUCTION}

Multiferroic materials that demonstrate a changed electric polarization by a magnetic field or a changed magnetization by an electric field have recently initiated enormous interest for their potential applications in the next-generation novel multifunction devices such as spintronics, data storage, sensors and so on ${ }^{1-12}$. The hexagonal manganites, with $\mathrm{RMnO}_{3}$ chemical formula, are good examples of multiferroic materials. Among these hexagonal manganites, $\mathrm{YMnO}_{3}(\mathrm{YMO})$ has attracted more attention owing

This is an Open Access article licensed under a Creative Commons license: Attribution 4.0 International (CC- BY). Published by Oriental Scientific Publishing Company @ 2018

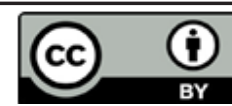


to its high ferroelectric transition temperature (TC 950 K) and anti-ferromagnetic transition temperature $(\mathrm{TN} \sim 75 \mathrm{~K})^{13,14}$. The crystal structure of $\mathrm{YMO}$ is formed by $\mathrm{MnO}_{5}$ trigonal bipyramids in which three in-plane and two apical oxygen ions surround individual manganese ion. In this structure, the ferroelectricity is related to the small tilting of $\mathrm{MnO}_{5}$ and trigonal bipyramids buckling of $Y$ layers. The origin of magnetism on the other hand is attributed to $\mathrm{Mn}^{3+}$ spins which align anti-ferromagnetically in the ab plane of $\mathrm{YMO}$ structure below $75 \mathrm{~K}^{15}$. YMO is considered as a good candidate for high temperature sensing and actuation applications due to i) its high Curie temperature, $~ 950 \mathrm{~K}$ and ii) being lead-free component. Most of the multiferroics have transition ions such as $\mathrm{Mn}^{3+}, \mathrm{Fe}^{3+}$, which have partially filled d-orbitals at their B-side atom ${ }^{16,17}$. Thermal conductivity of these materials is related to the variation of the oxidation state of transition ions. Therefore, most of the multiferroics demonstrate low polarization, poor dielectric features and high leakage current ${ }^{18}$. To minimize or eliminate such losses it is needed to understand the essence of electrical transport mechanism in multiferroic materials. Even though many works have been conducted to shed light on multiferroics properties of $\mathrm{YMO}$, there have been fewer reports regarding the electrical conductivity and dielectric properties of YMO at wide range temperature and frequency regions ${ }^{19-22}$. Various research groups have tried to modify the electrical and magnetic properties of this material via doping various elements on $Y$ and/or $\mathrm{Mn}$ atoms ${ }^{23-29}$. In those investigations the scientists employed different substitution elements such as Er, In, Ga, Co, Fe, Ru, Ni, Cu, Ti, Mo to observe the influence of those elements on magnetic and electrical features of $\mathrm{YMO}$.

\section{MATERIALS AND METHODS}

Yttrium nanostructured chromitemanganites doped with alkaline earth metals (Ca) were synthesized by sol-gel method. The influence of synthesis methods on the structure of synthesized chromite-manganites is studied. The XRD method was used to evaluate the characteristics of powder particles and the results showed that complex chromite-manganites have orthorhombic structure. Studies described $\mathrm{in}^{31}$ have shown that the formation of the crystal structure is a multistage process; the crystalline product is obtained at a temperature of $1100^{\circ} \mathrm{C}$. such particles are large and form large agglomerates. Therefore it makes sense to look for alternative methods for the synthesis of weakly agglomerated $\mathrm{Y}_{0,5} \mathrm{Ca}_{0,5} \mathrm{Cr}_{0,5} \mathrm{Mn}_{0,5} \mathrm{O}_{3}$ nanoparticles using organic compounds. Methods such as citratenitrate synthesis and sol-gel can be distinguished ${ }^{30}$. In these cases the formation of nanoparticles will occur either in the decomposition of previously formed organic complexes or in an isolated volume (trace elements) the parameters of which can be controlled by selecting different organic compounds. Therefore the aim of this study was the synthesis of nanoparticles of chromite-manganites doped with alkaline earth metals using the Sol-gel method and refinement of the composition of the obtained nanoparticles by X-ray. In this paper, we used the sol-gel method using glycerin as a precipitator.

Nanoparticles of manganite chromitemanganites doped with alkaline earth metals were synthesized by sol-gel method, where two different surfactants were used. The application of this method made it possible to obtain single-phase crystalline nanoparticles of chromite-manganites.

\section{Synthesis of chromium doped manganite}

A solid mixture $\mathrm{Y}_{0,5} \mathrm{Ca}_{0,5} \mathrm{Cr}_{0,5} \mathrm{Mn}_{0,5} \mathrm{O}_{3}$ synthesized for the first time.

The parameters of the single cell and X-ray and incometence density. To obtain the mangant formula ${ }_{0,5} \mathrm{Ca}_{0,5} \mathrm{Cr}_{0,5} \mathrm{Mn}_{0,5} \mathrm{O}_{3}$ mixtures of $\mathrm{Y}_{2} \mathrm{O}_{3}, \mathrm{CaCO}_{3}$, $\mathrm{Cr}_{2} \mathrm{O}_{3}, \mathrm{Mn}_{2} \mathrm{O}_{3}$ were stoichiometrically calculated and carried out by the sol-gel method. Stoichiometric amounts of oxides were mixed and triturated in an agate mortar to obtain a homogeneous mixture. Then the mixtures were subjected to repeat annealing in a furnace in the temperature range of $600-1100^{\circ} \mathrm{C}$ with increase temperature in every $100^{\circ} \mathrm{C}$. Annealing was made in 6 stages: I stage $-600^{\circ} \mathrm{C}$, II - stage $-700^{\circ} \mathrm{C}$, III - stage $800^{\circ} \mathrm{C}$, IV - stage $900^{\circ} \mathrm{C}, \mathrm{V}$ - stage $1000^{\circ} \mathrm{C}$, $\mathrm{VI}$ - stage $1100^{\circ} \mathrm{C}$ with a total duration of 39 hours. Intermediate grinding was made after each synthesis stage. Upon completion of the synthesis, the furnace was turned off and cooling of the obtained compound was in the cooling mode of the muffle furnace. The composition of the final products was controlled by the method of X-ray.

The formation of new phases was controlled by X-ray phase analysis, which was carried out on 
the X-ray diffractometer Miniflex 600 (Rigaku). XRF data can be used to identify the phase and relative percentages of the different phases of the prepared materials.

Microstructure of bulk samples was studied by scanning electron microscopy (SEM) JOEL JED2300 with approaching up to $\times 2000$ and the ability to conduct elemental analysis.

\section{RESULTS AND DISCUSSION}

Radiographs of the synthesized complex mixed chromite-manganite composition $Y_{0,5}$ $\mathrm{Ca}_{0,5} \mathrm{Cr}_{0,5} \mathrm{Mn}_{0,5} \mathrm{O}_{3}$ are presented in Fig. 1. In addition, the structural parameters such as lattice parameters ( $a, b$ and $c$ ), lattice volume, density are determined from the XRF data by mathematical calculations the results are presented in Table 2.

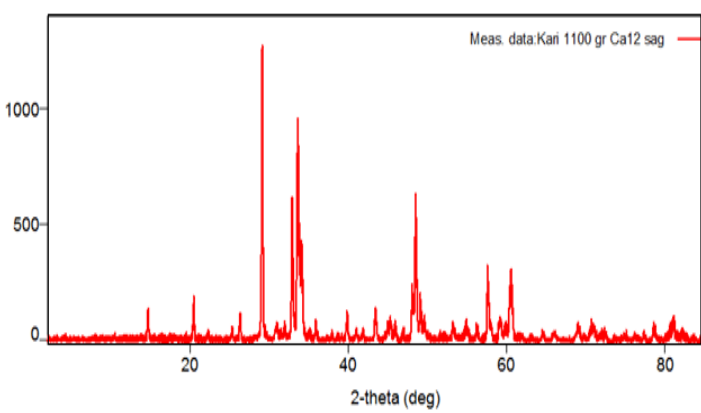

Fig. 1. XRD-patterns of chromium and calcium doped $\mathrm{YMnO}_{3}$

The data of the X-ray diffraction of the synthesized chromite-manganites are presented in Table 1.

According to X-ray diffraction data, the obtained chromite-manganites are orthorhombic with the spatial Pbam group (Table 2).

Data indexing of radiographs of synthesized chromite-manganites show that they have tetragonal structure with the following unit cell parameters:
1. $\mathrm{Y}_{0,5} \mathrm{Ca}_{0,5} \mathrm{Cr}_{0,5} \mathrm{Mn}_{0,5} \mathrm{O}_{3}-\alpha=5.429, \mathrm{~B}=7.507$,

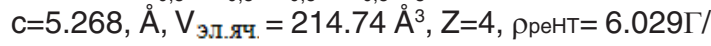
$\mathrm{cm}^{3}, \rho_{\text {пикн }}=6.021 \Gamma / \mathrm{cm}^{3}$.

The correctness of the indexing results is confirmed by a satisfactory coincidence of the experimental and calculated values of the inverse squares of the interplanar distances $\left(10^{4} / \mathrm{d}^{2}\right)$ as well as the degree of coincidence of the X-ray and pycnometric densities of the studied compounds.

SEM images of $\mathrm{Y}_{0,5} \mathrm{Ca}_{0,5} \mathrm{Cr}_{0,5} \mathrm{Mn}_{0,5} \mathrm{O}_{3}$ powders are illustrated in Fig. 2. On the surface it can be seeing that the resulting coating has a dense structure consisting of from 5 to $100 \mu \mathrm{m}$ crystals.

Table 1: Indexing of radiographs of synthesized phases

\begin{tabular}{|c|c|c|c|c|c|c|}
\hline No & [02Th.] & $\mathrm{d}[\mathrm{A}]$ & Int. [\%] & $10^{4} / \mathrm{d}^{2}$ exp. & hkl 1 & $10^{4} / \mathrm{d}^{2}$ theor. \\
\hline \multicolumn{7}{|c|}{$\mathrm{Y}_{0,5} \mathrm{Ca}_{0,5} \mathrm{Cr}_{0,5} \mathrm{Mn}_{0,5} \mathrm{O}_{3}$} \\
\hline 1 & 20.52 & 4.324 & 0.5 & 534.84 & $(0,1,1)$ & 533.75 \\
\hline 2 & 23.47 & 3.787 & 12.2 & 697.28 & $(1,0,1)$ & 696.21 \\
\hline 3 & 26.29 & 3.387 & 11.7 & 871.70 & $(1,1,1)$ & 870.50 \\
\hline 4 & 32.85 & 2.724 & 22.2 & 1347.68 & $(2,0,0)$ & 1346.55 \\
\hline 5 & 33.44 & 2.677 & 100.0 & 1395.41 & $(1,2,1)$ & 1394.31 \\
\hline 6 & 34.01 & 2.634 & 24.5 & 1441.34 & $(0,0,2)$ & 1440.26 \\
\hline 7 & 34.97 & 2.563 & 6.1 & 1522.30 & $(2,1,0)$ & 1521.70 \\
\hline 8 & 37.12 & 2.420 & 0.7 & 1707.53 & $(2,0,1)$ & 1706.83 \\
\hline 9 & 37.91 & 2.371 & 1.6 & 1778.84 & $(1,0,2)$ & 1777.94 \\
\hline 10 & 39.05 & 2.305 & 1.8 & 1882.16 & $(2,1,1)$ & 1881.35 \\
\hline 11 & 39.57 & 2.276 & 3.1 & 1930.43 & $(0,3,1)$ & 1929.76 \\
\hline 12 & 39.80 & 2.263 & 0.1 & 1952.67 & $(1,1,2)$ & 1951.47 \\
\hline 13 & 40.77 & 2.211 & 6.8 & 2045.60 & $(2,2,0)$ & 2044.89 \\
\hline 14 & 41.74 & 2.162 & 8.4 & 2139.38 & $(0,2,2)$ & 2138.65 \\
\hline 15 & 43.04 & 2.100 & 5.2 & 2267.57 & $(1,3,1)$ & 2266.23 \\
\hline 16 & 44.40 & 2.039 & 0.4 & 2405.27 & $(2,2,1)$ & 2404.48 \\
\hline 17 & 45.08 & 2.010 & 0.1 & 2475.18 & $(1,2,2)$ & 2474.32 \\
\hline 18 & 48.00 & 1.894 & 34.5 & 2787.66 & $(2,0,2)$ & 2786.93 \\
\hline 19 & 49.17 & 1.851 & 4.4 & 2918.68 & $(2,3,0)$ & 2917.26 \\
\hline 20 & 49.58 & 1.837 & 6.9 & 2963.34 & $(2,1,2)$ & 2962.34 \\
\hline 21 & 52.34 & 1.747 & 0.1 & 3276.53 & $(2,3,1)$ & 3275.29 \\
\hline 22 & 52.94 & 1.728 & 0.1 & 3348.97 & $(1,3,2)$ & 3347.26 \\
\hline 23 & 53.31 & 1.717 & 0.1 & 3392.02 & $(3,0,1)$ & 3391.83 \\
\hline 24 & 53.53 & 1.711 & 1.1 & 3415.85 & $(0,1,3)$ & 3414.09 \\
\hline 25 & 54.13 & 1.693 & 1.9 & 3488.88 & $(2,2,2)$ & 3487.15 \\
\hline 26 & 54.78 & 1.675 & 10.7 & 3564.26 & $(3,1,1)$ & 3563.90 \\
\hline 27 & 56.33 & 1.632 & 1.7 & 3754.56 & $(1,1,3)$ & 3753.17 \\
\hline
\end{tabular}

Table 2: Type of crystal system and unit cell parameters chromite-manganites of composition $\mathrm{Y}_{0,5} \mathrm{Ca}_{0,5} \mathrm{Cr}_{0,5} \mathrm{Mn}_{0,5} \mathrm{O}_{3}$

\begin{tabular}{llcccccccc}
\hline No & Formula & $\begin{array}{c}\text { Type of } \\
\text { symmetry }\end{array}$ & a, $\AA$ & b, $\AA$ & c, $\AA$ & $\begin{array}{c}\text { Vun.c., } \\
\AA^{3}\end{array}$ & Z & PX-ray & Ppyc \\
\hline $1 \quad \mathrm{Y}_{0,5} \mathrm{Ca}_{0,5} \mathrm{Cr}_{0,5} \mathrm{Mn}_{0,5} \mathrm{O}_{3}$ & orthorhombic & 5.42 & 7.51 & 5.26 & 214.74 & 4 & 6.03 & 6.02 \\
\hline
\end{tabular}


Figure 3 shows the semi-quantitative elemental analysis method $\mathrm{Y}_{0,5} \mathrm{Ca}_{0,5} \mathrm{Cr}_{0,5} \mathrm{Mn}_{0,5} \mathrm{O}_{3}$. The semi-quantitative elemental analysis revealed the presence of calcium and chromium in the $\mathrm{YMnO}_{3}$ structure. The elemental analysis performed on an electron-scanning microscope (insert in Fig. 3) showed that the atomic fractions of the elements practically coincide which corresponds to the formula of chromium and calcium doped yttrium manganite$\mathrm{Y}_{0,5} \mathrm{Ca}_{0,5} \mathrm{Cr}_{0,5} \mathrm{Mn}_{0,5} \mathrm{O}_{3}$. As can be seen from Fig. 3 the powders obtained by this technology are practically monodisperse which is a great advantage of the method.
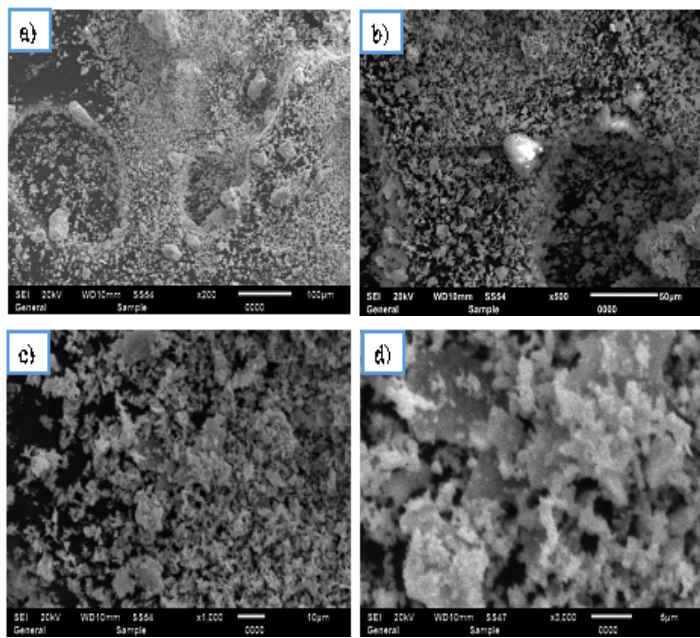

Fig. 2. SEM micrographs of $\mathrm{Y}_{0,5} \mathrm{Ca}_{0,5} \mathrm{Cr}_{0,5} \mathrm{Mn}_{0,5} \mathrm{O}_{3}$ a) an increase of 200, b) an increase of $500 \mathrm{~b}$ ) an increase of $1000, b)$ an increase of 2000

\section{CONCLUSION}

In this paper for the first time the problems of synthesis, X-ray analysis and crystal morphology of

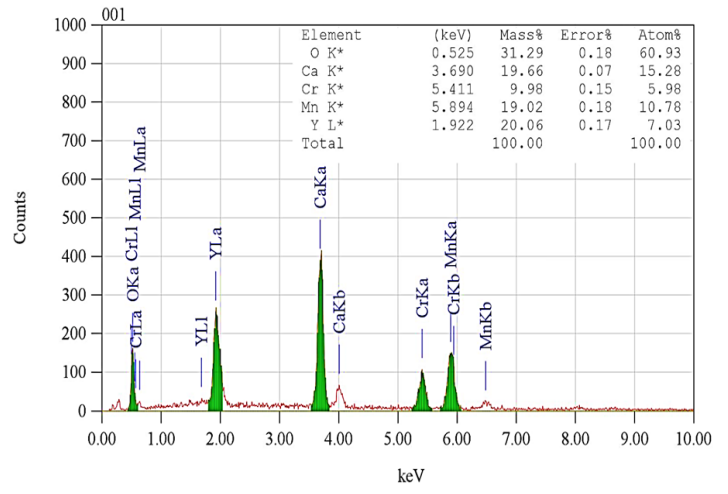

Fig. 3. Semi-quantitative elemental analysis of $\mathrm{Y}_{0,5} \mathrm{Ca}_{0,5} \mathrm{Cr}_{0,5} \mathrm{Mn}_{0,5} \mathrm{O}_{3}$

synthesized powders are considered. Radiographic method determined the type of symmetry and the parameters of the elementary cells. It was found that chromite-manganites obtained by sol-gel crystallize in the orthorhombic structure and correspond to the formula $\mathrm{Y}_{0,5} \mathrm{Ca}_{0,5} \mathrm{Cr}_{0,5} \mathrm{Mn}_{0,5} \mathrm{O}_{3}$. According to the results of scanning electron microscope synthesized chromite-manganite consists of crystals from 5 to 100 microns.

\section{ACKNOWLEDGEMENT}

This article was prepared with the financial support of the grant of the Ministry of Education and Science of the Republic of Kazakhstan No05130165 "Development and physical basis of new crystal systems in the class of multiferroics.

\section{Conflict of Interest}

The authors declare no confilict of interest.

\section{REFERENCES}

1. Murugavel P.; Padhan P.; Prellier W. Appl. Phys. Lett., 2004, 85, 4992-4994.

2. Lottermoser T.; Lonkai T.; Amann U.; Hohlwein D.; Ihringer J.; Fiebig M. Nature., 2004, 430, 541-544.

3. Zheng H.; Wang J.; Lofland S.E.; MohaddesArdabili Z. Ma, L.; Zhao T.; Salamanca- Riba L.; Shinde S.R.; Ogale S.B.; Bai F.; Viehland D.; Jia Y.; Schlom D.G.; Wuttig M.; Roytburd A.; Ramesh R. Science., 2004, 303, 661.

4. Spaldin N.A.;. Fiebig M. Science., 2005, 309, 391-392.
5. Singh M.P.; Prellier W.; Simon C.; Raveau B. Appl. Phys. Lett., 2005, 87, 022505-3.

6. Dong S.X.; Zhai J.Y.; Wang N.G.; Bai F.M.; Li J.F.; Vieland D.; Lograsso T.A. Appl. Phys. Lett., 2005, 87, 222504-3.

7. Wang N.G.; Cheng J.; Pyatakov A.; Zvezdin A.K.; Li J.F., Cross L.E.; Vieland D. Phys. Rev., B. 2005, 72, 104434-5.

8. Nan C.W.; Liu G.; Lin Y.H.; Chen H.D. Phys. Rev. Lett., 2005, 94, 197203.

9. Slutsker J.; Levin I.; Li J.H.; Artemev A.; Royburd A.L. Phys. Rev. B., 2006, 73, 184127. 
10. Wu T.; Zurbuchen M.A.; Saha S.; Wang R.V.; Streiffer S.K.; Mitchell J.F. Phys. Rev. B., 2006, 73, 134416.

11. YamasakiY.; MiyasakaS.; KanekoY.;HeJ.P.; Arima T.; Tokura Y. Phys. Rev. Lett., 2006, 96, 249902.

12. Qi X.; Dho J.; Tomov R.; Blamire M.G.; MacManus-Driscoll J. L. Appl. Phys. Lett., 2005, 86, 062903(1)-062903(3).

13. Ismailzade I.G.; Kizhaev S.A. Sov. Phys. Solid State., 1965, 7, 236-238.

14. Smolenskii G.A.; Chupis I.E. Sov. Phys. Usp., 1982, 25, 475-493.

15. Munoz A.; Alonso J.A.; Martinez-Lope M.J.; Casais M.T.; Martinez J.L.; Fernandez-Diaz M.T. Phys. Rev. B., 2000, 62, 9498-9510.

16. Catalan G.; Scott J. F. Adv. Mater., 2009, 21, 2463-2485.

17. Kimura T.; Kawamoto S.; Yamada I.; Azuma M.; Takano M.; Tokura Y. Phys. Rev. B., 2003, 67, 180401(R).

18. Wang K.F.; Liu J.M.; Ren Z.F. Adv. Phys., 2009, 58, 321-448.

19. Rao G.V.; Wanklyn B.M.; Rao C.N.R. J. Phys. Chem. Solids., 1971, 32, 345.

20. Tomczyk M.; Vilarinho P.M.; Moreira A.; Almeida A. J. Appl. Phys., 2011, 110, 064116.

21. Adem U.; Mufti N.; Nugroho A.A.; Catalan G.; Noheda B.; Palstra T. T. M. Journal of Alloys and Compounds., 2015, 638, 228-232.
22. Ren P.; Fan H.; Wang X. Appl. Phys. Lett., 2013, 103, 152905.

23. Katsufuji T.; Masaki M.; Machida A.; Moritomo M.; Kato K.; Nishibori E.; Takata M.; Sakata M.; Ohoyama K.; Kitazawa K.; Takagi H. Phys. Rev. B., 2002, 66, 134434(1)-134434(8).

24. vanAkenB.B.;BosJ.W.G.; de GrootR.A.;PalstraT.T. M. Phys. Rev. B., 2001, 63125127(1)-125127(4).

25. Sharma N.; Das A.;. Mishra S.K.;. Prajapat C.L.; Singh M.R.; Meena S. S. Journal of Applied Physics., 2014, 115, 213911.

26. Park J.; Kang M.; Kim J.; Lee S.; Jang K.H., Pirogov A.; Park J.G.; Lee C.; Park S.H.; Kim H.C. Phys. Rev. B., 2009, 79, 064417-1- 064417-6.

27. Malo S.; Maignan A. Materials Research Bulletin., 2012, 47, 974-979.

28. Thakur R.K.; Thakur R.A.; Kaurav N.; Ganesan V.; Gaur N.K. Journal of Alloys and Compounds., 2016, 688, 280-287.

29. Gutiérrez D.; Peña O.; Ghanimi K.;Durán P.; Moure C. J. Phys. Chem. Solids., 2002, 63, 1975-1982.

30. Mataev M.M.; Saxena S.M.; Patrin G.S.; Tursinova Zh.Y.; Kezdikbayeva A.T.; Nurbekova M. A.; Baitasheva G.U. Orient. J. Chem., 2018, 34(3), 1312-1316.

31. Mataev M.M.; Patrin G.S.; Tursinova Zh.Y.; Abdraimova M.R.; Yurkin G. Yu. Journal of Siberian Federal University. Mathematics \& Physics., 2018, 11(4), 411-41. 